\title{
Bleeding manifestations in dengue and their correlation with the platelet count
}

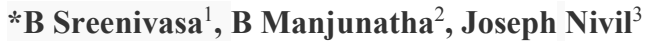

Sri Lanka Journal of Child Health, 2017; 46(3): 218-221

\begin{abstract}
Objective: To study the common bleeding manifestations in dengue and see whether there is a correlation between them and platelet counts less than 100,000/cu.mm.
\end{abstract}

Method: Children below the age of 14 years with dengue seropositivity were included in the study. Relevant blood investigations were done and patients were managed according to World Health Organisation guidelines.

Results: A total of 100 children with a mean age of $7.9 \pm 3.7$ years were included in the study. During the course of illness, bleeding occurred in $60 \%$ of children. It was found that $26 \%$ of children had melaena, $20 \%$ had petechiae, $8 \%$ had haematemesis, $4 \%$ had epistaxis and $2 \%$ had gum bleeding. All $(100 \%)$ the patients who had platelet counts between 50,001-100,000/cu.mm developed haemorrhage and $95.8 \%$ of patients with platelet range between 20,001-50,000/cu.mm of blood had developed haemorrhage. However, of patients who had platelet counts less than 20,000/cu.mm, 41.8\% developed haemorrhage and $58.2 \%$ did not have haemorrhagic manifestations $(\mathrm{p}=0.001)$.

Conclusions: No correlation was found between platelet counts $<100,000 / \mathrm{cu} \mathrm{mm}$ and increase in incidence of bleeding manifestations in DHF.

DOI: http://dx.doi.org/10.4038/sljch.v46i3.8320

(Key words: Dengue haemorrhagic fever, bleeding, platelet count, thrombocytopenia, coagulation).

\section{Introduction}

Dengue is an arboviral infection transmitted through

${ }^{1}$ Basaveshwara Medical College Hospital and Research Centre, Chitradurga, India, ${ }^{2}$ Chitradurga, Balaji Children Clinic, Holalkere, India, ${ }^{3}$ Chitradurga, SJM College of Pharmacy, India

*Correspondence: sreenivasab@ymail.com

(Received on 09 September 2016: Accepted after revision on 21 October 2016)

The authors declare that there are no conflicts of interest

Personal funding was used for the project.

Open Access Article published under the Creative

Commons Attribution CC-BY (c) (P) License. the bite of the Aedes mosquito ${ }^{1}$. In developing countries epidemics are becoming more frequent straining the limited resources of the public health system ${ }^{1}$. Many dengue fever cases are self-limiting, but the complications, such as haemorrhage and shock can be life threatening ${ }^{2}$. Dengue haemorrhagic fever (DHF) ranks high among the newly emerging infectious diseases of public health significance and is the most important of the arthropod borne viral diseases ${ }^{3}$. Approximately 2.5 billion people live in dengue-risk regions with about 100 million new cases each year worldwide ${ }^{4}$.

\section{Objective}

To study common bleeding manifestations in DHF and see whether there is a correlation between them and platelet counts less than 100,000/cu.mm.

\section{Method}

A prospective observational study was conducted in Basaveshwara Medical College Hospital, Chitradurga from April to August 2016 on children less than 14 years of age who were seropositive for dengue. The inclusion criteria were as follows:

- Seropositivity for any one or all of NS1 Ag, IgM and IgG antibodies for dengue.

- An acute febrile illness lasting for 2-7 days, with any one or more of the following:

$\begin{array}{ll}\circ & \text { Myalgia } \\ \circ & \text { Headache } \\ \circ & \text { Retro-orbital pain } \\ \circ & \text { Vomiting } \\ \circ & \text { Abdominal pain } \\ \circ & \text { Hepatomegaly } \\ \circ & \text { Jaundice } \\ \circ & \text { Seizures } \\ \circ & \text { Spontaneous bleeding } \\ & \text { manifestations } \\ & \text { Thrombocytopenia with platelet } \\ & \text { counts less than 100,000/cu.mm, } \\ & \text { or evidence of plasma leakage i.e. } \\ \text { pleural effusion, ascites or } \\ \text { hypoproteinaemia, with or } \\ \text { without signs of circulatory } \\ \text { failure. }\end{array}$

The exclusion criteria were as follows:

- All subjects seronegative for NS1Ag, IgM and IgG antibodies for dengue.

- Subjects with a history of bleeding disorders of other aetiology such as 
Bleeding manifestations in dengue and their...Sri Lanka Journal of Child Health, 2017; 46(3): 218-221

immune thrombocytopenic purpura, haemophilia etc.

The first 100 seropositive children who fulfilled the inclusion criteria were included in the study. Detailed demographic data, clinical history, physical examination findings and relevant baseline investigations (haemoglobin level, total leucocyte and differential count, platelet count, packed cell volume) were recorded as per pre-designed proforma. The children were managed as per World Health Organisation (WHO) guidelines ${ }^{4}$. The cases were followed-up daily for the clinical and laboratory parameters till they were discharged. Haemoglobin level, platelet count and packed cell volume were done at least once per day and at more frequent intervals in children admitted to the paediatric intensive care unit (PICU). Prothrombin time (PT), activated partial thromboplastin time (APTT), international normalised ratio (INR), aspartate aminotransferase (AST), alanine aminotransferase (ALT) and serum albumin were done as and when needed. Chest $\mathrm{x}$-ray and ultrasonogram (USG) of abdomen were done to see capillary leak whenever needed. Widal test, test for malaria parasite, blood urea, serum creatinine, etc. were done when the clinical history and symptoms prompted us to do the same for diagnosis and management.

Descriptive statistics were used. Chi-square test was done to find out the association between two attributes using SPSS for windows (version 16.0). $\mathrm{p}<0.05$ was considered statistically significant. ratios, percentages and proportions were used wherever necessary.

\section{Results}

A total of 100 serologically positive dengue cases, with mean age of $7.9 \pm 3.7$ years, were included in the study. Males were 53\% and females $47 \%$. Other than fever, which was present in all cases, the most common presenting complaints were vomiting (26\%), headache $(10 \%)$, black coloured stool $(6 \%)$ and bleeding (5\%). During the course of the illness, bleeding occurred in $60 \%$ of the children. Whilst $26 \%$ had melaena, $20 \%$ had petechiae, $8 \%$ had hematemesis, $4 \%$ had epistaxis and $2 \%$ had gum bleeding. None of the children with bleeding had received non-steroidal anti-inflammatory drugs (NSAIDS)

Among the bleeding children, mean AST was 128.6 IU/L (normal 1-55 IU/L), mean ALT 40.2 IU/L (normal 5-45 IU/L), mean PT $20.396 \pm 16.269$ seconds (normal range 13.5 to 100 seconds), mean APTT $40 \pm 13.7$ seconds (normal range 30.8 to 100 seconds) and the mean INR was 2.65. Signs of capillary leak were observed in $69 \%$ of children and $11 \%$ had experienced shock. Whilst $20 \%$ and $18 \%$ of patients respectively developed signs of capillary leak on day 4 and day 5 of illness, 13\% developed signs of capillary leak on day 6 of illness. Range of onset of capillary leak was between 2 nd and 8 th day (Mean=4.7).

A comparison of the mean haemoglobin, PCV and platelet counts on admission and during bleeding is shown in Table 1.

Table 1: Comparison of mean haemoglobin, PCV and platelet counts on admission and during bleeding

\begin{tabular}{|l|c|c|c|}
\hline \multicolumn{1}{|c|}{ Parameter } & On admission & During bleeding & P value \\
\hline Haemoglobin $(\mathrm{g} / \mathrm{dl})$ & 13.17 & 7.65 & 0.001 \\
\hline PCV & 39.64 & 23.13 & 0.002 \\
\hline Platelet count (per cu mm) & $41,861.6$ & 17,198 & 0.0001 \\
\hline
\end{tabular}

There was a statistically significant fall in haemoglobin, PCV and platelet count during bleeding (Table 1).

Among the 100 children studied $24 \%$ had leucopenia, $17 \%$ had leucocytosis and $59 \%$ had normal leucocyte counts. Of the 100 children, 41 had dengue serology suggestive of primary dengue and 59 had dengue serology suggestive of secondary dengue. Of the children with primary dengue 24 $(58.5 \%)$ had bleeding manifestations predominantly petechiae, whereas $36(61 \%)$ of the children with secondary dengue had bleeding manifestations predominantly melaena and haematemesis. Two children died, both cases of secondary dengue.

The relationship between dengue shock and platelet counts is shown in Table 2.

Table 2: Relationship between shock and platelet counts

\begin{tabular}{|c|c|c|c|c|}
\hline \multirow[t]{2}{*}{ Shock } & \multicolumn{3}{|c|}{ Platelet count per cu mm } & \multirow{2}{*}{$\begin{array}{c}\text { Total } \\
\text { Number }(\%)\end{array}$} \\
\hline & $\begin{array}{c}<20,000 \\
\text { Number }(\%)\end{array}$ & $\begin{array}{c}20,000-50,000 \\
\text { Number }(\%)\end{array}$ & $\begin{array}{c}50,001-100,000 \\
\text { Number }(\%) \\
\end{array}$ & \\
\hline Yes & $02(08.0)$ & $04(09.3)$ & $05(15.6)$ & $11(11.0)$ \\
\hline No & $23(92.0)$ & $39(90.7)$ & $27(84.4)$ & $89(89.0)$ \\
\hline Total & $25(100.0)$ & $43(100.0)$ & $32(100.0)$ & $100(100.0)$ \\
\hline
\end{tabular}


Of the 11 patients with dengue shock, $15.6 \%$ had platelet counts from 50,001-100,000 per cu mm, $9.3 \%$ had platelet counts from $20,000-50,000$ per cu $\mathrm{mm}$ and $8 \%$ had platelet counts less than 20,000 per cu mm. The relationship between shock and platelet counts was not statistically significant.

The relationship between dengue haemorrhage and platelet counts is shown in Table 3.

Table 3: Relationship between haemorrhage and platelet counts during course of illness

\begin{tabular}{|l|c|c|c|c|}
\hline \multirow{2}{*}{ Haemorrhage } & \multicolumn{3}{|c|}{ Platelet count per cu mm } & \multirow{2}{*}{$\begin{array}{c}\text { Total } \\
\text { Number (\%) }\end{array}$} \\
\cline { 2 - 5 } & $\begin{array}{c}<\mathbf{2 0 , 0 0 0} \\
\text { Number (\%) }\end{array}$ & $\begin{array}{c}\mathbf{2 0 , 0 0 0}-\mathbf{5 0 , 0 0 0} \\
\text { Number (\%) }\end{array}$ & $\begin{array}{c}\mathbf{5 0 , 0 0 1 - 1 0 0 , 0 0 0} \\
\text { Number (\%) }\end{array}$ & \\
\hline Yes & $28(41.8)$ & $23(95.8)$ & $09(100.0)$ & $60(60.0)$ \\
\hline No & $39(58.2)$ & $01(04.2)$ & 00 & $40(40.0)$ \\
\hline Total & $67(100.0)$ & $24(100.0)$ & $09(100.0)$ & $100(100.0)$ \\
\hline
\end{tabular}

All the patients who had platelet counts between 50,001-100,000/cu.mm developed haemorrhage and $95.8 \%$ of patients with platelet counts between 20,000-50,000/cu.mm developed haemorrhage. However, of the 67 patients who had platelet counts less than 20,000/cu.mm, $41.8 \%$ developed haemorrhage whilst $58.2 \%$ did not. This is statistically significant. ( $\mathrm{P}=0.001 ; \mathrm{p}<0.01)$.

The relationship between the bleeding pattern and platelet counts during the course of illness is shown in Table 4.

Table 4: Relationship between the bleeding pattern and platelet counts during course of illness

\begin{tabular}{|l|c|c|c|c|}
\hline \multirow{2}{*}{ Bleeding } & \multicolumn{3}{|c|}{ Platelet count per cu mm } & \multirow{2}{*}{$\begin{array}{c}\text { Total } \\
\text { Number (\%) }\end{array}$} \\
\cline { 2 - 5 } & $\begin{array}{c}<\mathbf{2 0 , 0 0 0} \\
\text { Number (\%) }\end{array}$ & $\begin{array}{c}\mathbf{2 0 , 0 0 0 - 5 0 , 0 0 0} \\
\text { Number (\%) }\end{array}$ & $\begin{array}{c}\mathbf{5 0 , 0 0 1 - 1 0 0 , 0 0 0} \\
\text { Number (\%) }\end{array}$ & \\
\hline No bleeding & $39(58.2)$ & $01(04.2)$ & 00 & $40(40.0)$ \\
\hline Melaena & $13(19.4)$ & $08(33.3)$ & $05(55.6)$ & $26(26.0)$ \\
\hline Haematemesis & $03(04.5)$ & $04(16.7)$ & $01(11.1)$ & $08(08.0)$ \\
\hline Petechiae & $09(13.4)$ & $08(33.3)$ & $03(33.3)$ & $20(20.0)$ \\
\hline Epistaxis & $01(01.5)$ & $03(12.5)$ & 00 & $04(04.0)$ \\
\hline Gum bleeding & $02(03.0)$ & 00 & 00 & $02(02.0)$ \\
\hline Total & $67(100.0)$ & $24(100.0)$ & $09(100.0)$ & $100(100.0)$ \\
\hline
\end{tabular}

Among patients with bleeding manifestations, $53.3 \%$ patients had hepatomegaly, $(26.6 \%)$ being in patients who had platelet counts $<20,000$ per cu mm. Among patients without bleeding manifestations, $40 \%$ patients had hepatomegaly, $37.5 \%$ being in patients who had platelet counts less than 20,000 per cu $\mathrm{mm}$. This was not statistically significant.

In our study of 100 children of DHF, NS1 Ag was positive only in $28 \%$ of cases, NS1 Ag and $\operatorname{IgM}$ was positive in $12 \%$, IgM only was positive in $1 \%$, IgM and IgG was positive in $25 \%$, NS1 Ag, IgM, IgG was positive in $15 \%$, NS1 $\mathrm{Ag}$, IgG was positive in $8 \%$, IgG was positive only in $11 \%$ of cases.

\section{Discussion}

In our study bleeding occurred in $60 \%$ of patients, $34 \%$ having gastrointestinal (GI) bleeding (26\% melaena, $8 \%$ haematemesis), $20 \%$ having petechiae, $4 \%$ having epistaxis and $2 \%$ having gum bleeding. Our study is similar to that of Ahmed MM, ${ }^{5}$ who found haematemesis in 19\%, gum bleeds in $16 \%$, epistaxis in $12 \%$, melaena in $8 \%$ and subconjunctival haemorrhage in $4 \%$. It is also similar to a study by Ratageri et al. ${ }^{6}$ where GI bleeds were seen in $22 \%$ and petechiae in $18 \%$. However, a study done by Kishore et al., ${ }^{7}$ showed haemorrhage into skin (purpura, petechiae or ecchymoses) as the commonest manifestation of bleeding (17\%).

In our study platelet counts less than 100,000 per cu $\mathrm{mm}$ were present in all dengue patients. A study by Kulkarni et al., ${ }^{3}$ revealed thrombocytopenia in $84 \%$ of children with dengue and a study by Ahmed $\mathrm{MM}^{5}$ revealed thrombocytopenia was seen in $68.5 \%$ dengue patients. However, in a study by Banerjee $e t$ $a l .{ }^{8}$, thrombocytopenia was seen in only $19 \%$ dengue patients. In our study, $9 \%$ of patients had platelet counts between 50,000-100,000/cu. mm, $24 \%$ had platelet counts between 20,000-50,000 /cu.mm and $67 \%$ had platelet counts less than $20,000 /$ cu.mm. In a study by Malavige et al. ${ }^{10}$, $24.2 \%$ had platelet counts between 50,000$100,000 / \mathrm{cu} \mathrm{mm}, 46 \%$ had platelet counts between $20,000-50,000 / \mathrm{cu} \mathrm{mm}$ and $30 \%$ had platelet counts less than $20,000 /$ cu.mm. In a study by Kamath et al., ${ }^{10}, 62.3 \%$ had platelet counts less than 50,000/cu.mm. 
In our study whilst $100 \%$ patients who had platelet count between 50,001-100,000/cu.mm developed haemorrhage and $95.8 \%$ patients with platelet counts between 20,000-50,000/cu.mm developed haemorrhage, only $41.8 \%$ patients who had platelet counts less than 20,000/cu.mm developed haemorrhages. Our observations were similar those of Joshi et $a l .{ }^{1}$, Sunil Gomber et $a l .{ }^{11}$, and Dhooria et $a l .{ }^{12}$ who also found poor correlation between thrombocytopenia and bleeding manifestations. No correlation was found between reducing trend of platelet count and increase in incidence of bleeding manifestations indicating that abnormal platelet aggregation or disseminated intravascular coagulation may have a role in bleeding in DHF cases rather than reduction in absolute numbers as the cause of bleeding manifestations. However, a study by Narayanan et $a .^{2}$, showed that bleeding has a correlation to platelet count only when it is less than 50,000/cu.mm of blood.

\section{Conclusions}

- In $58.5 \%$ children with primary dengue, petechiae, epistaxis, gingival bleeding were the common bleeding manifestations whereas in $61 \%$ children with secondary dengue melaena and haematemesis were the common bleeding manifestations.

- There was no correlation between platelet counts below 20,000 per cu $\mathrm{mm}$ and bleeding manifestations.

\section{References}

1. Joshi R, Baid V. Profile of dengue patients admitted to a tertiary hospital in Mumbai. Turkish Journal of Pediatrics 2011; 53:626-31.

PMid: 22389984

2. Narayan M, Aravind MA, Ambikapathy P, Prema R, Jeyapaul MP. Dengue fever: clinical and laboratory parameters associated with complications. Dengue Bulletin 2003; 27.

3. Kulkarni MJ, Sarathi V, Bhalla V, Shivpuri D, Acharya U. Clinico-epidemiological profile of children hospitalized with dengue. Indian Journal of Pediatrics 2010; 77:1103-7. https://doi.org/10.1007/s12098-010-02022

PMid: 20890686

4. World Health Organization. Dengue guideline for diagnosis, treatment, prevention and control: Geneva WHO; 2011.
5. Ahmed M.M. Clinical profile of dengue fever infection in King Abdul Aziz University Hospital Saudi Arabia. Journal of Infection in Developing Countries 2010; 4(8):503-10.

https://doi.org/10.3855/jidc. 1038

PMid: 20818102

6. Ratageri VH, Shepur TA, Wari PK, Chavan SC, Mujahid IB, Yergolkar PN. Clinical profile and outcome of dengue fever cases. Indian Journal of Pediatrics 2005; 72(8):705-6.

https://doi.org/10.1007/BF02724083

PMid: 16131779

7. Kishore J, Singh J, Dhole TN, Ayyagari A. Clinical and serological study of first large epidemic of dengue in and around Lucknow, India, in 2003. Dengue Bulletin 2006; 30 .

8. Banerjee M, Chatterjee T, Choudhary G S, Srinivas V, Kataria V K. Dengue: A clinico-haematological profile. Medical Journal Armed Forces India 2008; 64(4): 333-6.

https://doi.org/10.1007/BF02724083

PMid: 16131779

9. Malavige G N, Ranatunga P K, Jayaratne S $\mathrm{D}$ et al. Dengue viral infections as cause of encephalopathy. Indian Journal of Medical Microbiology 2007; 25(2):143-5. https://doi.org/10.4103/0255-0857.32722 PMid: 17582186

10. Kamath SR, Ranjit S. Clinical features, complications and atypical manifestations of children with severe forms of dengue haemorrhagic fever in South India. Indian Journal of Pediatrics 2006; 73(10): 88995.

https://doi.org/10.1007/BF02859281

11. Gomber S, Ramachandran VG, Kumar S, Agarwal KN, Gupta P, Dewan DK. Haematological observations as diagnostic markers in dengue haemorrhagic fever: A reappraisal. Indian Pediatrics 2001; 38: 477-81.

PMid: 11359973

12. Dhooria GS, Bhat D, Bains HS. Clinical profile and outcome in children of dengue fever in North India. Iranian Journal of Pediatrics 2008; 18(03):222-8. 